\title{
Neuropsychological Profile of Anti-NMDA Receptor Encephalitis
}

\author{
Laura Marcos-Arribas ${ }^{1}$, Justino Jiménez Almonacid ${ }^{2}$, Alberto Marcos Dolado ${ }^{2 *}$ \\ ${ }^{1}$ Social and Human Sciences Faculty, Comillas Pontifical University, Madrid, Spain \\ ${ }^{2}$ Neurology Department, Hospital Clínico San Carlos, Madrid, Spain \\ Email: ${ }^{3}$ amarcosdolado@gmail.com
}

Received July $25^{\text {th }}, 2013$; revised August $27^{\text {th }}, 2013$; accepted September $28^{\text {th }}, 2013$

\begin{abstract}
Copyright (C) 2013 Laura Marcos-Arribas et al. This is an open access article distributed under the Creative Commons Attribution License, which permits unrestricted use, distribution, and reproduction in any medium, provided the original work is properly cited.
\end{abstract}

\begin{abstract}
Anti-N-methyl-d-aspartate (NMDA) receptor encephalitis is a life-threatening disorder that often occurs as a paraneoplastic encephalitis and usually begins with neuropsychological or psychiatric symptoms. We report a case of NMDA receptor encephalitis due to an ovarian teratoma, which began with severe and progressive amnesia and behavioral changes, reversed after surgical treatment and plasmapheresis. Using a battery of cognitive tests, its neuropsychological profile before treatment showed a complete alteration of the short and long term memory of both verbal and visual fixation, with clear improvement with cues and with intrusions, and saving other cognitive domains, such as working, episodic and semantic memory, executive, visuospatial, praxical thinking and language functions. These deficits reverted to normalcy with treatment. So, we can conclude that anti-NMDA receptor encephalitis is a rare entity that can be potentially serious depending on early management and diagnosis. We must suspect this entity in children or young people presenting with behavioural disturbances and crisis, with a cognitive pattern of complete alteration in short and long term memory improving with cues, and respecting other cognitive domains.
\end{abstract}

Keywords: Anti-NMDA Receptor Encephalitis; Ovarian Teratoma; Amnestic Syndrome; Priming; Neuropsychology

\section{Introduction}

Anti-N-methyl-d-aspartate (NMDA) receptor encephalitis is a life-threatening disorder that often occurs as a paraneoplastic neuropsychiatric encephalitis (Rosenfeld, 2011). It predominantly affects young women with a strong association with ovarian teratomas but can be recognized also in women without tumors, in men and in children (Dalmau, 2008; Prüss, 2010; Dalmau, 2011). Its frequency and prevalence is unknown because of the rarity of its appearance. Due to the role that NMDA receptor plays in learning this entity normally begins with memory deficits, but also with psychiatric symptoms and seizures. The presence of type NMDA autoantibodies in serum or cerebrospinal fluid is specific for this novel disorder and has changed not only the diagnosis of the entity but also the concept of inmunomediated cerebral disorders (Suzuki, 2013; Rosenfeld \& Titulaer, 2012). The removal of the ovarian teratoma and the early immunological treatment improves the prognosis decreasing the risk of recurrence, but the early diagnosis only depends on prompt suspicion and the rapid recognition of its clinical manifestations (Iizita, 2010; Johnson, 2010; Alexopoulos, 2011; Young 2013). And although the initial and predominant presentation of this disease is the neuropsychological clinic, little information about the cognitive deficits is available (Finke, 2012).

Therefore, we report a case of a NMDA receptor encephalitis due to an ovarian teratoma who debuted with severe and pro-

\footnotetext{
"Corresponding author.
}

gressive amnesia and behavioral changes, describing her attentional, mnesic, executive, linguistic and praxis profiles before and after successful treatment.

\section{Case Report}

A 24-year-old woman was taken to the emergency room by her colleagues for consistent behavior disorders, repeating recurring questions and difficulties completing routine daily job duties. She had no personal or family history of medical or neurological diseases. She had been working in a management company for six months, and was highly educated. She was not taking any medications or recreational drugs, but consumed alcohol occasionally.

Although the clinical picture was exacerbated in the day of admission, similar difficulties had been progressively presented all along the previous month, with lack of flexibility, mental rigidity, emotional lability and irritability. She does not complain of headache or fever. The general exam was normal but hyperperspiration.

The neurological examination in the emergency room showed a normal consciousness level with good collaboration but suspicious behavior. The language was normal in comprehension, repetition, naming and fluency. There was no negligence. A short memory deficit was evident, with inability to recognize the examiner after five minutes, repeated questions about her situation, normal event and semantic memory with lacunar retrograde amnesia regarding recent weeks. Visual field, 
eye fundus, pupils, cranial nerves exam, motor, sensory and coordination systems, reflexes and gait were normal. No meningeal signs were present.

From a behavioral point of view during examination the patient worked at any time in carrying out the tests. She has a great interest on what her condition was, showing a good sense of humor, sometimes joking. Despite this, the patient was nervous throughout the whole process, worrying constantly about the reason for the evaluation, and how she would recover from what was going on. Sometimes she showed frustration or irritability when not performing either an exercise or when we did not explain her exactly what we are testing. Because of her fixing inability she sometimes feels disoriented and with repeated blocked moments. She also had episodic psychomotor agitation and anxiety, referred to taste "glue" sensations. The patient had partial knowledge of the problem and stated "I was living like the movie Memento". She needed to write down everything that she could not remember from what had been explained, visits, etc.

With a suspected syndromic diagnosis of subacute anterograde amnesia due to limbic or autoimmune encephalitis we began treatment with an antiepileptic drug and performed a cranial tomography scan, blood and cerebrospinal fluid analysis, all reported as normal. The patient was admitted to study and a magnetic resonance imaging and breast exploration showed no abnormalities. During admission, the patient had fluctuating behavior disorders such as psychomotor agitation, mild desinhibition, bad mood and some delusions. She also presents no response to external stimuli episodes, lasting seconds. And EEG was normal but for diffuses low waves. The gynecological ultrasound exam detected a tumor in the left ovary, suggestive of teratoma. Surgery was scheduled.

Then we performed the following neuropsychological battery:

- Information and orientation subtest of the Weschler Memory Scale III (WMS-III).

- Logical Memory I and II of the WMS-III.

- Semantic memory.

- Episodic memory.

- Couple of words I and II of the WMS-III.

- Symbols subtest of the WAIS-III.

- Word List of the WMS-III.

- Letter-Number sequencing of the WMS-III.

- Digit span, both in forward and reverse order.

- Rey-Osterrieth Complex Figure (Figures 1 and 2).

- Visual Photo-test (Carnero, 2004).

- Boston Naming Test (30 items).

- Memory Imparment Screen (MIS) (Buschke, 1999).

- Overlaping figure test of Poppelreuter.

- Ideomotor praxias.

- Ideative praxias.

- Bimanual and unimanual sequencing task.

- Graphic programming (Figures 3 and 4).

- Abstract thinking.

- Semantic errors inhibition.

- FAS.

- Bimanual Luria maneuver.

The patient underwent surgery within 7 days since admission and the diagnosis of mature ovarian teratoma was confirmed by pathology studies. Nine alternate days sessions of plasmapheresis were then started. The presence of antibodies directed against the NMDA receptor was confirmed in cefalospinal fluid.

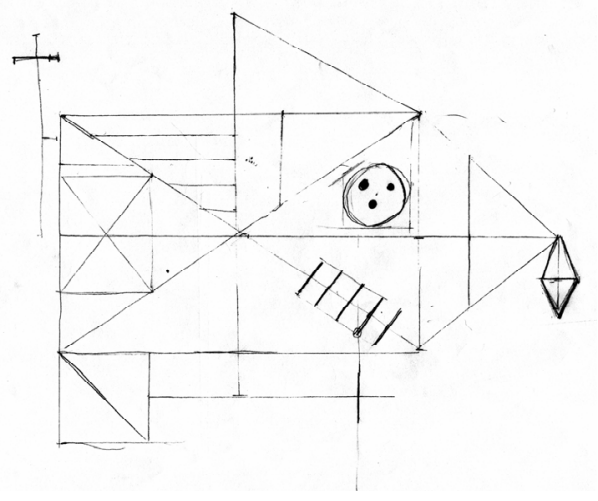

Figure 1.

Rey-Osterrieth Complex Figure copy.

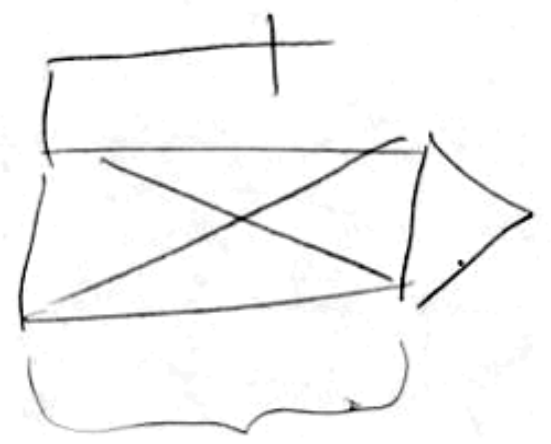

Figure 2.

Rey-Osterrieth Complex Figure immediate recall.

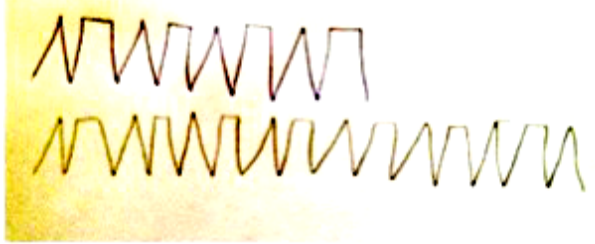

Figure 3.

Alternating programming.
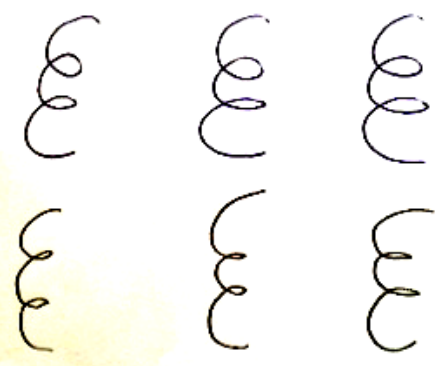

Figure 4.

Graphic loops.

After one month we repeated the neuropsychological battery. The previous and final results were shown in Table 1, and Figures 5-7. As we see, the patient regained almost normal mental state in four weeks, and gradually all behavioral disorders 


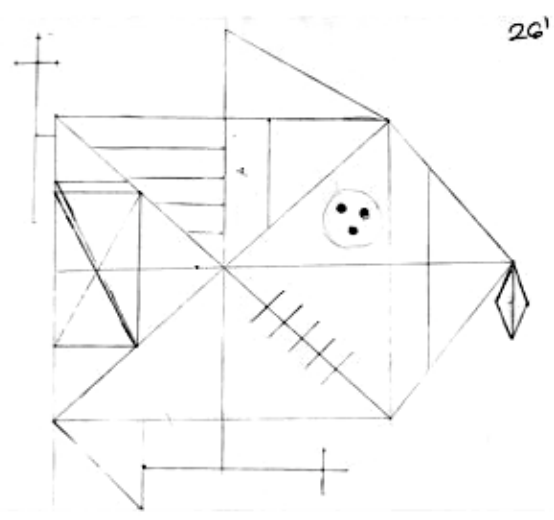

Figure 5.

Rey-Osterrieth Complex Figure copy after treatment.

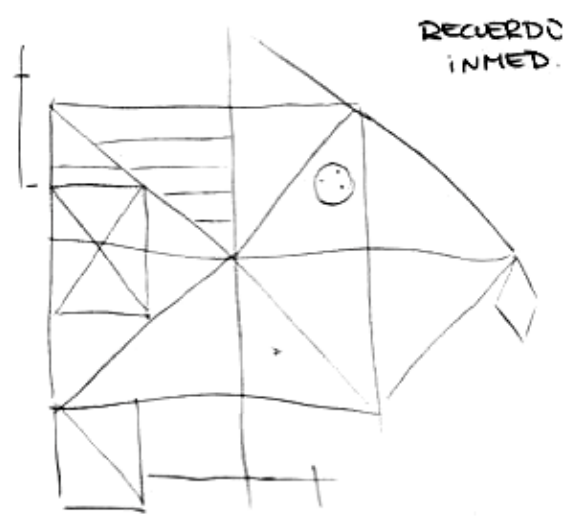

Figure 6.

Rey-Osterrieth Complex Figure immediate recall after treatment.

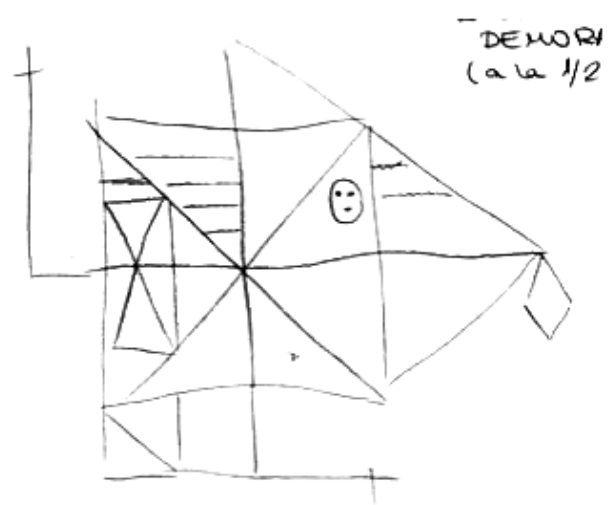

Figure 7.

Rey-Osterrieth Complex Figure delayed recall after treatment.

and seizures disappeared. After 4 months of follow-up she remains asymptomatic having recovered their normal complex functionality.

\section{Discussion}

In a patient with abrupt onset of short term memory loss, behavioural changes and temporal lobe seizures we classically must discard limbic encephalitis (Zuliani, 2012). In the last few years the encephalitis associated with NMDA receptor antibodies has been characterised as distinct forms from the limbic encephalitis, above all because of the higher proportion of patients are children or young women initially admitted to emergency hospitals for acute anxiety, behavioural change or psychosis (Rosenfeld \& Dalmau, 2012). Anti-NMDA receptor encephalitis belongs to the group known as paraneoplastic neurological syndromes, which are a rare and heterogeneous group of diseases that can affect any area of the nervous system having in common their association with cancer (often hidden in the time of clinical onset) and a likely autoimmune pathogenesis (Rosenfeld, 2011). Specifically, the anti-NMDA antibodies associated with different types of extra-limbic encephalitis and limbic structures has recently partnered with a neurological syndrome characterized by disturbances of consciousness, involuntary movements and seizures (Dalmau, 2008; Lebon, 2012; Waas, 2012). It is considered as a paraneoplastic syndrome associated primarily with ovarian tumors in young women, but can occur in the absence of neoplasia. In most cases, we can detect also severe alterations of consciousness, dysautonomia, complex involuntary movements, hyperthermia and respiratory failure requiring treatment in intensive care units.

In our case, we directly search for an underlying tumor due to clinical debut and having ruled other entities out with additional studies. We do not wait for confirmation with autoimmune antibody assays, as this usually comes belatedly, so that does not change the initial management.

Usually, tumor resection leads to complete recovery of clinical with few long-term neurological sequels (Tanyi, 2012; Boeck, 2013; Dabner, 2012; Pham, 2011; Titulaer, 2013). It so occurred in our patient, with complete recovery of initial deficits in about a month of evolution. But not rarely, this entity can have a poor neurological recovery with permanent deficits (Armangue, 2012; Peery, 2013).

The clinical onset of this entity is similar in signs and symptoms to other diseases, so only high clinical suspicion lead to an early diagnosis. Given the large impact on the prognosis of early institution of treatment, it is a priority to know their neuropsychological profile to suspect the entity among compatible cases. At admission our patient showed severe impairment of short-term memory and memory setting, presenting a retrograde gap about the facts of the last two months. She also showed a mild impairment in working memory and attention, without alterations in semantic and episodic memories, executive, visuospatial, praxical, thinking and language functions.

To be more specific, testing the Information and Orientation part of the WMS-III, the patient was oriented in person, but not in time or space. We can explain this altered alopsiquic consciousness by the absence of mnemonic fixation.

In Logical Memory task of WMS-III she obtained very low scores, with a learning curve with negative value, indicating not only that there was no learning but there were also information lost between B1 to B2 stories. Furthermore, the total score in Logical Memory II have decreased until zero since the first presentation, representing a null retention. However, the total score on Recognition of Logical Memory was high for both A and B stories, indicating a good facilitated cued recall.

In the Rey Complex Figure the patient reported difficulties to hold and handle the pencil but clear apraxia was not evident. The copy was made in 24 minutes, for her high perfectionism and obsessive behavior, without visuospatial or praxical deficits. 


\section{MARCOS-ARRIBAS ET AL.}

Table 1.

Neuropsychological battery scores before and after treatment.

\begin{tabular}{|c|c|c|}
\hline & Before Treatment & After Treatment \\
\hline $\begin{array}{l}\text { Information and Orientation } \\
\text { (WMS III) }\end{array}$ & $9 / 13$ & $11 / 13$ \\
\hline \multirow{6}{*}{ Logical Memory I } & Story A: $10 / 25$ & Story A: 21/25 \\
\hline & Story B1: 9/25 & Story B1: $13 / 25$ \\
\hline & Story B2: $8 / 25$ & Story B2: 19/25 \\
\hline & Total (A+B1): 19/50 & Total $(\mathrm{A}+\mathrm{B} 1): 34 / 50$ \\
\hline & Total (A+B1+B2): 27/75 & Total (A+B1+B2): 53/75 \\
\hline & Learning curve (B2-B1): -1 & Learning curve (B2-B1): 6 \\
\hline $\begin{array}{l}\text { Logical Memory } \\
\text { (WMS III) }\end{array}$ & Story A: 0/25 & Story A: 20/25 \\
\hline Logical Memory II & Story B1: $0 / 25$ & Story B1: $17 / 25$ \\
\hline & Total $(\mathrm{A}+\mathrm{B}): 0 / 50$ & Total $(\mathrm{A}+\mathrm{B}): 35 / 50$ \\
\hline Recognition & $\begin{array}{l}\text { Story A: } 10 / 15 \\
\text { Story B: } 10 / 15\end{array}$ & $\begin{array}{l}\text { Story A: } 13 / 15 \\
\text { Story B: } 14 / 15\end{array}$ \\
\hline Retention Percentage & $0 \%$ & $87.5 \%$ \\
\hline Semantic Memory & $14 / 15$ & $14 / 15$ \\
\hline Episodic Memory & $10 / 10$ & $10 / 10$ \\
\hline \multirow{5}{*}{$\begin{array}{l}\text { Couple of Words } \\
\text { (WMS III) }\end{array}$} & List A: $0 / 8$ & List A: $5 / 8$ \\
\hline & List B: $0 / 8$ & List B: 7/8 \\
\hline & List C: $2 / 8$ & List C: $8 / 8$ \\
\hline & List D: $1 / 8$ & List D: $8 / 8$ \\
\hline & Learning slope (List D-A): 1 & Learning slope (List D-A): 3 \\
\hline Couple of Words II & Total score: $0 / 8$ & Total score: $8 / 8$ \\
\hline Recognition & $16 / 24$ & $24 / 24$ \\
\hline Retention Percentage & $0 \%$ & $100 \%$ \\
\hline $\begin{array}{l}\text { Symbols } \\
\text { (WAIS III) }\end{array}$ & $\begin{array}{l}\text { Hits: } 43 \\
\text { Mistakes: } 1 \\
\text { Immediate Recall: 0/9 }\end{array}$ & $\begin{array}{l}\text { Hits: } 45 \\
\text { Mistakes: } 5 \\
\text { Immediate Recall: 9/9 }\end{array}$ \\
\hline $\begin{array}{l}\text { Word List } \\
\text { (WMS III) }\end{array}$ & $\begin{array}{l}\text { List A: } \\
\quad \text { First trial: } 7 / 12 \\
\text { Second trial: } 5 / 12 \\
\text { Third trial: } 5 / 12 \\
\text { Fourth trial: } 6 / 12 \\
\text { Intrusions: } 1 \\
\text { Total score: } 23 / 48 \\
\text { List B: } 4 / 12 \\
\text { Intrusions: } 2 \\
\text { List A Recall: } 0 / 12 \\
\text { First contrast (List A first trial-List B): } 3 \\
\text { Learning curve (List A fourth trial-List A first trial): }-1 \\
\text { Second contrast (List A fourth trial-List A recall): } 5\end{array}$ & $\begin{array}{l}\text { List A: } \\
\text { First trial: } 6 / 12 \\
\text { Second trial: } 10 / 12 \\
\text { Third trial: } 10 / 12 \\
\text { Fourth trial: } 12 / 12 \\
\text { Intrusions: } 1 \\
\text { Total score: } 38 / 48 \\
\text { List B: } 7 / 12 \\
\text { Intrusions: } 0 \\
\text { List A Recall: } 10 / 12 \\
\text { First contrast (List A first trial-List B): }-1 \\
\text { Learning curve (List A fourth trial-List A first trial): } 6 \\
\text { Second contrast (List A fourth trial-List A recall): } 2\end{array}$ \\
\hline $\begin{array}{l}\text { Letter-Number } \\
\text { (WMS III) }\end{array}$ & $9 / 27$ & $11 / 27$ \\
\hline Digit Span & $\begin{array}{l}\text { Forward order: } 9 / 16 \\
\text { Reverse order: } 7 / 14 \\
\text { Total: } 16 / 30\end{array}$ & $\begin{array}{l}\text { Forward order: } 10 / 16 \\
\text { Reverse order: } 8 / 14 \\
\text { Total: } 18 / 30\end{array}$ \\
\hline Rey-Osterrieth Complex Figure & $\begin{array}{l}\text { Copy: } 36 / 36 \text { ( } 24 \text { minutes }) \\
\text { Immediate recall: } 3 / 36 \text { ( } 1 \text { minute }) \\
\text { Delayed recall: } 0 / 36\end{array}$ & $\begin{array}{l}\text { Copy: } 36 / 36 \text { ( } 26 \text { minutes) } \\
\text { Immediate recall: } 28 / 36 \text { ( } 4 \text { minute) } \\
\text { Delayed recall: } 29 / 36 \text { ( } 5 \text { minute })\end{array}$ \\
\hline Visual Photo-test & 36 & 47 \\
\hline Boston Naming Test (30) & 28 & 30 \\
\hline MIS of Buschke & $0 / 8$ & $8 / 8$ \\
\hline Poppelreuter & $15 / 15$ & $15 / 15$ \\
\hline Ideomotor Praxias & $\begin{array}{l}\text { Right } \operatorname{arm} 6 / 6 \\
\text { Left arm } 6 / 6 \\
\text { Bimanual } 3 / 3\end{array}$ & $\begin{array}{l}\text { Right } \operatorname{arm} 6 / 6 \\
\text { Left arm } 6 / 6 \\
\text { Bimanual } 3 / 3\end{array}$ \\
\hline Ideative Praxias & $\begin{array}{l}\text { Right arm } 3 / 3 \\
\text { Left arm } 3 / 3 \\
\text { Bimanual } 2 / 2\end{array}$ & $\begin{array}{l}\text { Right } \operatorname{arm} 3 / 3 \\
\text { Left arm } 3 / 3 \\
\text { Bimanual } 2 / 2\end{array}$ \\
\hline Sequencing Task & $\begin{array}{l}\text { Right arm } 1 / 1 \\
\text { Left arm } 1 / 1 \\
\text { Bimanual } 1 / 1\end{array}$ & $\begin{array}{l}\text { Right arm } 1 / 1 \\
\text { Left arm } 1 / 1 \\
\text { Bimanual } 1 / 1\end{array}$ \\
\hline
\end{tabular}




\begin{tabular}{lll}
\hline Graphic Programming & $6 / 6$ & $6 / 6$ \\
Abstract Thinking & $12 / 12$ & $12 / 12$ \\
Semantic Errors Inhibition & $4 / 5$ & $5 / 5$ \\
\multirow{2}{*}{ FAS } & F: 20 & F: 21 \\
& A: 21 & A: 25 \\
Bimanual Luria Maneuver & S: 20 & S: 23 \\
& Right arm $1 / 1$ & Right arm $1 / 1$ \\
\hline
\end{tabular}

She did all copy taking reference measurements with the pencil using the paper as a rod, jumping from one line to another although the form was not completed and repeating some steps. In the Immediate Recall test, which took exactly one minute, she obtained an extremely low score, indicating a huge failure of retention. In the Delayed Recall test she did not only forgot the figure but also did not remembered having been copying or watching it, showing total anterograde amnesia.

In the first completion of Couples of Words of WMS-III she obtained a very low learning slope. The patient was unable to respond almost a single right word and invented words with similar semantic categories. The word pairs recalling was null, showing angry because of it, improving a lot the recognition later. The same happened with the delayed recall, obtaining a $0 \%$ of retention percentage.

The performance of copy part of the Symbols test in WAIS-III was appropriate, but she showed an inadequate capacity to retain any symbol.

In the Word List test from the WMS-III, the patient showed a very low grade of retention being the last words the most repeated, with some intrusions. The delayed recall was again very poor since she could not remember any word. With the successive repetitions she obtained a negative learning curve, meaning anterograde amnesia.

In the Letter-Number test in WMS-III the patient's score was very low for her inability to remember the slogan, showing that short memory is also altered.

The working memory was adequate, with normal score in the Digit Span, direct and reverse, like her executive function. The semantic and episodic memories were assessed with two sets of structured questions on general knowledge and past events. Both were normal.

To evaluate the visual memory we performed a Spanish validate test, the Photo-Test of Carnero et al. (Carnero, 2004). This test shows six objects for patient to name, performing it after an interference task, evoking male names for a half-minute, and woman names for a half-minute more. Then the patient is asked for the pictures. We can provide cues if not remembered by the patient. The patient obtained a normal score on gender name fluency, but a null visual delayed recall, with good recovery after cues. We can conclude something similar about the MIS, with null delayed memory, although in this case she did not improve with cues.

We cannot observe any difficulties in language evocation in Boston Naming Test or fluency in FAS, visuospatial perception on Poppelreuter, apraxic or disexecutive disturbance on bimanual and unimanual sequencing task and Luria, graphic programming, semantic errors inhibition and abstract thinking.

With the evolution we show a clear improvement of the cognitive and behavioral picture of the patient within almost the normal score range on the neuropsychological battery. As sig- nificant data outside the normal in this second cognitive assessment, we found the results of Symbols and Letter-Number tests. We can probably explain this because the patient was somewhat inattentive and trying to finish fast the examination.

In addition, throughout the interview was evident great improvement in the recognition with cues, above all in Logical Memory, Couple of Words and Photo Test. Given that in this type of encephalitis the main involvement are the hippocampal and limbic systems, one would expect an absence of gain with tracks, as in all the hippocampal memory models. But, this is not our patient's case, and suggests to us a beneficial effect of priming, which cannot be explained by other means or cognitive resources.

Therefore, we can characterize the neuropsychological profile of the NMDA receptor encephalitis as a complete alteration of the short and long memory of both verbal and visual fixation, with clear improvement with cues for priming effect and with intrusions, and saving other cognitive domains, as working and semantic memories, executive, visuospatial, praxical, thinking and language functions.

\section{Conclusion}

Anti-NMDA receptor encephalitis is a rare entity that can be potentially very serious, depending the complete reversal of the deficits and good prognosis on the early treatment. Since this disease usually debuts with cognitive and behavioural symptoms, a neuropsychological characterization is essential to help the early diagnosis. We must suspect this entity in children or young people presenting with behavioural disturbances and crisis, with a complete alteration of the short and long memory improving with cues, and respecting other cognitive domains.

\section{Acknowledgements}

The authors thank M. J. García Barrero for reviewing the manuscript.

\section{REFERENCES}

Alexopoulos, H., Kosmidis, M. L., Dalmau, J., \& Dalakas, M. C. (2011) Paraneoplastic anti-NMDAR encephalitis: Long term follow-up reveals persistent serum antibodies. Journal of Neurology, 258, 15681570. http://dx.doi.org/10.1007/s00415-011-5982-4

Armangue, T., Petit-Pedrol, M., Dalmau, J. (2012). Autoimmune encephalitis in children. Journal Child Neurology, volume 11, pages 1460-9. http://dx.doi.org/10.1177/0883073812448838

Boeck, A.L., Logemann, F., Krauß, T., Hussein, K., Bültmann, E., Trebst, C., \& Stangel, M. (2013). Ovarectomy despite negative imaging in anti-NMDA receptor encephalitis: Effective even late. Case Reports in Neurological Medicine, 2013, Article ID: 843192.

Buschke, H., Kuslansky, G., Katz, M., Stewart, W. F., Sliwinski, M. J., Eckholdt, H. M., \& Lipton, R. B. (1999). Screening for dementia 
withthe memory impairment screen. Neurology, 2, 231-238. http://dx.doi.org/10.1212/WNL.52.2.231

Carnero, C., \& Montoro, M. T. (2004). El Test de las Fotos. Revista de Neurología, 9, 801-806.

Dalmau, J., Gleichman, A. J., Hughes, E. G., et al. (2008) AntiNMDA-receptor encephalitis: Case series and analysis of the effects of antibodies. The Lancet Neurology, 7, 1091-1098. http://dx.doi.org/10.1016/S1474-4422(08)70224-2

Dabner, M., McCluggage, W. G., Bundell, C., Carr, A., Leung, Y., Sharma, R., \& Stewart, C. J. (2012). Ovarian teratoma associated with anti-N-methyl D-aspartate receptor encephalitis: A report of 5 cases documenting prominent intratumoral lymphoid infiltrates. International Journal of Gynecological Pathology, 31, 429-437. http://dx.doi.org/10.1097/PGP.0b013e31824a1de2

Dabner, M., McCluggage, W. G., Bundell, C., Carr, A., Leung, Y., Sharma, R., \& Stewart, C. J. (2012). Ovarian teratoma associated with anti-N-methyl D-aspartate receptor encephalitis: A report of 5 cases documenting prominent intratumoral lymphoid infiltrates. International Journal of Gynecological Pathology, 31, 429-437. http://dx.doi.org/10.1097/PGP.0b013e31824a1de2

Finke, C., Kopp, U. A., Prüss, H., Dalmau, J., Wandinger, K. P., \& Ploner, C. J. (2012). Cognitive deficits following anti-NMDA receptor encephalitis. Journal of Neurology, Neurosurgery \& Psychiatry, 83, 195-198. http://dx.doi.org/10.1136/jnnp-2011-300411

Iizuka, T., Yoshii, S., Kan, S., et al. (2010). Reversible brain atrophy in anti-NMDA receptor encephalitis: A long-term observational study. Journal of Neurology, 257, 1686-1691. http://dx.doi.org/10.1007/s00415-010-5604-6

Johnson, N., Henry, C., Fessler, A. J., \& Dalmau, J. (2010). AntiNMDA receptor encephalitis causing prolonged nonconvulsive status epilepticus. Neurology, 75, 1480-1482. http://dx.doi.org/10.1212/WNL.0b013e3181f8831a

Lebon, S., Mayor-Dubois, C., Popea, I., Poloni, C., Selvadoray, N., Gumy, A., \& Roulet-Perez, E. (2012). Anti-N-methyl-D-aspartate (NMDA) receptor encephalitis mimicking a primary psychiatric disorder in an adolescent. Journal of Child Neurology, 27, 1607-1610. http://dx.doi.org/10.1177/0883073812438099

Peery, H. E., Day, G. S., Doja, A., Xia, C., Fritzler, M. J., \& Foster, W. G. (2013). Anti-NMDA receptor encephalitis in children: The disorder, its diagnosis, and treatment. Handbook of Clinical Neurology, 112, 1229-1233. http://dx.doi.org/10.1016/B978-0-444-52910-7.00045-3

Pham, H. P., Daniel-Johnson, J. A., Stotler, B. A., Stephens, H., \& Schwartz, J. (2011). Therapeutic plasma exchange for the treatment of anti-NMDA receptor encephalitis. Journal of Clinical Apheresis, 26, 320-325. http://dx.doi.org/10.1002/jca.20311

Prüss, H., Dalmau, J., Harms, L., Höltje, M., Ahnert-Hilger, G., Borowski, K., Stoecker, W., \& Wandinger, K. P. (2010). Retrospective analysis of NMDA receptor antibodies in encephalitis of unknown origin. Neurology, 75, 1735-1739. http://dx.doi.org/10.1212/WNL.0b013e3181fc2a06

Rosenfeld, M. R., Dalmau, J. (2011). Anti-NMDA-receptor encephalitis and other synaptic autoimmune disorders. Current Treatment Options in Neurology, 13, 324-332. http://dx.doi.org/10.1007/s11940-011-0116-y

Rosenfeld, M. R., \& Dalmau, J. O. (2012). Paraneoplastic disorders of the CNS and autoimmune synaptic encephalitis. Continuum (Minneaplis, Minn), 2, 366-383.

http://dx.doi.org/10.1212/01.CON.0000413664.42798.aa

Rosenfeld, M. R., Titulaer, M. J., \& Dalmau, J. (2012). Paraneoplastic syndromes and autoimmune encephalitis: Five new things. Neurology Clinical Practice, 2, 215-223. http://dx.doi.org/10.1212/CPJ.0b013e31826af23e

Suzuki, S., Seki, M., \& Suzuki, N. (2013). Recent concept of limbic encephalitis: Progress in anti-NMDA receptor encephalitis. Japanese Journal of Clinical Immunology, 36, 86-94. http://dx.doi.org/10.2177/jsci.36.86

Tanyi, J. L., Marsh, E. B., Dalmau, J., \& Chu, C. S. (2012). Reversible paraneoplastic encephalitis in three patients with ovarian neoplasms. Acta Obstetricia et Gynecologica Scandinavica, 91, 630-634.

Titulaer, M. J., McCracken, L., Gabilondo, I., et al. (2013). Treatment and prognostic factors for long-term outcome in patients with antiNMDA receptor encephalitis: An observational cohort study. The Lancet Neurology, 12, 157-165. http://dx.doi.org/10.1016/S1474-4422(12)70310-1

Young, P. J., Baker, S., Cavazzoni, E., Erickson, S. J., Krishnan, A., Kruger, P. S., Rashid, A. H., \& Wibrow, B. A. (2013). A case series of critically ill patients with anti N-methyl-D-aspartate receptor encephalitis. Critical Care and Resuscitation, 1, 8-14.

Waas, J. A., \& Storm, A. H. (2012). Anti-NMDA-receptor encephalitis: A neuropsychiatric illness requiring further study. Tijdschrift voor Psychiatrie, 54, 279-283.

Zuliani, F., Graus, F., Giometto, B., et al. (2012). Central nervous system neuronal surface antibody associated syndromes: Review and guidelines for recognition. Journal of Neurology, Neurosurgery \& Psychiatry, 83, 638-645.

http://dx.doi.org/10.1136/jnnp-2011-301237 